\title{
Protocol Information Office
}

National Cancer Institute

\section{Source}

National Cancer Institute. Protocol Information Office. NCI Thesaurus. Code C70829.

An office within $\mathrm{NCl}$ which provides administrative support for clinical trial development and tracking by abstraction of key elements into a web-based relational database, monitoring trial timelines and activity from trial proposal to close-out, supporting document review and agent meetings, and developing metrics for program evaluation. 